ORIGINAL ARTICLE

\title{
Can rock climbing lead to Dupuytren's disease?
}

\author{
A J Logan, G Mason, J Dias, N Makwana
}

Br J Sports Med 2005;39:639-644. doi: 10.1136/bjsm.2004.015792

See end of article for authors' affiliations

.....................

Correspondence to: Mr Logan, Department of Orthopaedics, Wrexham Maelor Hospital, Cardiff CF23 8NH, UK ; andrew.logan@ ntlworld.com

Accepted 11 January 2005

\begin{abstract}
Objectives: To determine if rock climbing is a significant factor in the development of Dupuytren's disease in men, and, if so, what is the most likely related factor.

Methods: Questionnaires were distributed to all 1100 members of the Climbers' Club of Great Britain. These detailed basic information about the climber, the presence of Dupuytren's disease, and any known risk factors for its development.

Results: About half (51\%) of the questionnaires were returned. The respondents were almost entirely male. It was revealed that $19.5 \%$ of male climbers had developed Dupuytren's disease. There was a significantly higher life time intensity of climbing activity in those with the disease. An earlier age of onset of the disease was found in climbers compared with the general population.

Conclusions: This study further strengthens the hypothesis that repetitive trauma to the palmar fascia predisposes to the development of Dupuytren's disease in men.
\end{abstract}

$\mathrm{T}$ he aetiology of Dupuytren's disease is unclear and many predisposing conditions have been implicated. While ascending a wall or rock face, rock climbers use a number of different hand holds to support a large proportion of their body weight, subjecting the hands to large forces. These forces put considerable pressure on the fascia and other soft tissues of the hand while placing tremendous strain on the tendons and pulleys. We investigated whether the repetitive minor trauma to the palmar fascia during rock climbing could predispose to the development of Dupuytren's disease in men.

\section{METHODS}

A questionnaire was sent to all 1100 members of the Climbers' Club of Great Britain. The questionnaire consisted of five main sections. The first section recorded basic information about the climber such as occupation, age, sex, height, weight, and handedness. The second listed known risk factors for Dupuytren's disease including family history, blood group, manual occupation, alcohol consumption, smoking, and prescribed treatment for epilepsy. The third section enquired about climbing history to date. The fourth section required the climber to itemise the type and severity of any previous wrist or hand injury, including fractures, dislocations, crush injuries, burns, cuts, abrasions, and tendon damage. The final section asked if the climber had had Dupuytren's disease and provided diagrams for the respondent to illustrate the area of the hand affected. The disease severity of each finger could be marked on corresponding illustrations of fingers in various degrees of flexion (fig 1). An explanation of the study and questionnaire, including details of Dupuytren's disease and the signs to look for, was attached as a separate document.

\section{The population sample}

The Climber's Club of Great Britain was selected to provide the sample of climbers. Established in 1898, it now has over a 1000 members. Most become members at around the age of 30 and essentially join for life, giving a wide age distribution within the club. The club membership gives a snapshot of the prevalence of Dupuytren's disease across a number of age groups. To obtain membership, the climber must climb with existing members for about one year and then formally apply for membership with references from existing members. This study therefore focuses on dedicated and experienced climbers who are likely to climb regularly during their active climbing career and to a high standard. Importantly, it has a club committee supportive of the project and a Climber's Club magazine, which provided a means for distribution of the questionnaires.

\section{Climbing intensity calculations}

Details of each member's rock climbing history were recorded. Every climbing route is graded according to difficulty using international grading systems. The English adjusted technical grading is from moderate to extreme 10 (table 1). The grading scores given were converted into the English adjusted technical grade. For each climber the amount of climbing per year and the average technical grade at which they climbed during each decade of their climbing career to date was noted. Each adjusted grade was scored from 3 (moderate) to 20 (extreme 10) (table 1).
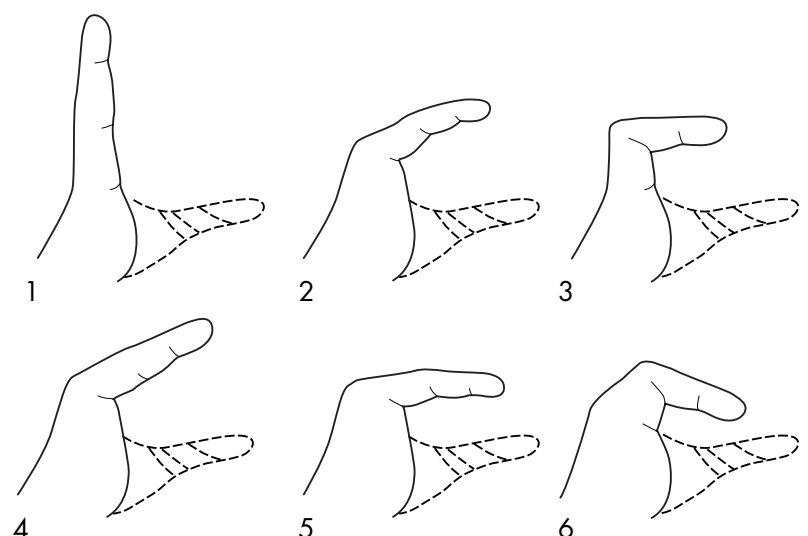

4
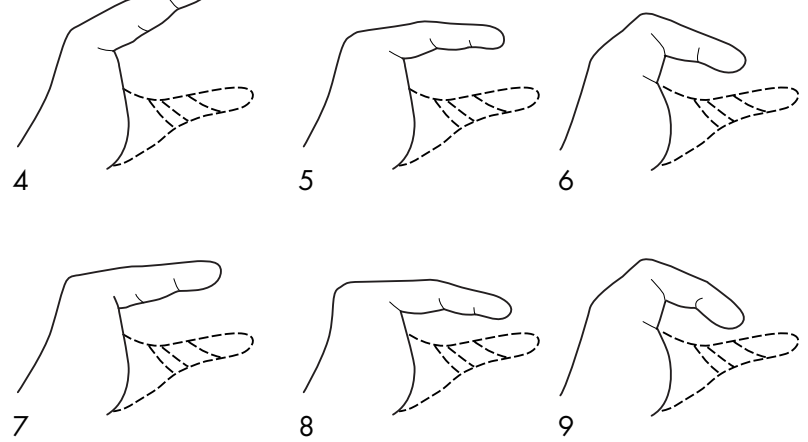

Figure 1 Severity grading score of each finger. 


\begin{tabular}{ll}
$\begin{array}{l}\text { Table } 1 \\
\text { adjusted }\end{array}$ & $\begin{array}{c}\text { Multiple assigned to each English } \\
\text { techical grade }\end{array}$ \\
\hline Score & $\begin{array}{l}\text { English adjusted } \\
\text { technical grade }\end{array}$ \\
\hline 3 & Moderate \\
4 & Difficult \\
5 & Very difficult \\
6 & Hard very difficult \\
7 & Severe \\
8 & Hard severe \\
9 & Very severe \\
10 & Hard very severe \\
11 & Extreme 1 \\
12 & Extreme 2 \\
13 & Extreme 3 \\
14 & Extreme 4 \\
15 & Extreme 5 \\
16 & Extreme 6 \\
17 & Extreme 7 \\
18 & Extreme 8 \\
19 & Extreme 9 \\
20 & Extreme 10 \\
\hline
\end{tabular}

From these details, the score assigned to each adjusted technical grade (3-20) was multiplied by the average number of days a year that the climber had spent climbing at that grade for each decade. The same was calculated for every decade that each climber had climbed for his or her whole climbing career to date. All technical grade scores for each climber were added together producing a total climbing intensity score for that climber (table 2 ).

This single numerical value for each climber represented the lifetime exposure to rock climbing. From this information, the pattern and prevalence of Dupuytren's disease could be compared with the intensity of climbing.

\section{Statistical analysis}

Statistical significance was calculated using an independent samples $t$ test for normally distributed data and the MannWhitney U test for data not normally distributed. Pearson's product moment correlation coefficient was used to identify a correlation between groups and the $\chi^{2}$ test for categorical data. A nominal value of $\mathrm{p}<0.05$ was used to establish significance.

\section{RESULTS}

A total of 562 questionnaires were returned (51\%), 17 of which were incomplete and omitted from the study. Data were complete in 545 cases $(50 \%)$. Most (498) responders were male, with just $8.6 \%$ being female. Because of the small number of women in this sample, only male responders were included in the analysis. The mean age of the climbers at the time of questionnaire completion was 54 years (range 23-93), and this confirmed the "membership for life" scenario. The total number of male climbers with Dupuytren's disease was 97. This gave an overall prevalence of $19.5 \%$. The mean age of climbers with Dupuytren's disease was 58.4 years (33-85), compared with 52.6 years (23-93) for the rest. Figures 2 and 3 illustrate the age of onset and age distribution of the disease respectively. The finger most commonly affected was the ring finger followed by the little then middle finger, the index finger being least often involved. The pattern of disease was similar in both the left and right hands (fig 4). Overall, $52 \%$ of the fingers involved had only thickening of the fascia and nodules, with no reported finger flexion deformities.

The average climbing intensity score in the climbers with Dupuytren's disease was 2635, compared with 2071 in those without. The difference is significant. A significant correlation was shown between the severity and age of onset of disease $(r=-0.241, \mathrm{p}=0.017)$, with an earlier onset of the disease being associated with an increased severity of contractures (fig 5).

Table 3 shows other possible risk factors.

A positive family history was noted in $16 \%$ of those with the disease, compared with $4 \%$ in those without which was a significant difference $(\mathrm{p}<0.001)$. There was no significant difference between the presence or absence of a history of smoking, alcohol consumption, or epilepsy between the Dupuytren's and non-Dupuytren's groups. Daytime occupations were studied because repetitive manual work is a proposed aetiological factor. Occupations most likely to involve some degree of repetitive manual work are: engineering, building, gardening/farming, and geology. There was no significant difference in the proportion of climbers with manual occupations in the disease and non-disease groups. There was no significant difference between the Dupuytren's and non-Dupuytren's group with respect to previous wrist and hand injuries. If all climbers with a family history of the disease are excluded from the analysis, the prevalence of Dupuytren's is $15.9 \%$ in men.

\section{DISCUSSION}

Dupuytren's disease is a condition resulting from the formation of fibrous bands, cords, and nodules in the palmar fascia and fingers, which can be palpated in those affected. Gradual contraction of these cords brings about the development of fixed flexion deformities in the fingers, which may be progressive. The disease is thought to have originated among the Vikings ${ }^{11}$ and is found most commonly in populations of Northern European origin, with a prevalence of $19.2 \%$ in men of all ages, rising to $39.5 \%$ in the $70-74$ year old age group. ${ }^{12}$ In the United Kingdom the prevalence in the general population depends on geographical location ranging from $4 \%$ of men living in Crewe $^{13}$ to $39 \%$ of men from the

Table 2 Calculation of total climbing intensity scores

\begin{tabular}{|c|c|c|c|}
\hline Age (years) & $\begin{array}{l}\text { Average number of climbing } \\
\text { days per year }\end{array}$ & Average grade of climbing & Score per decade \\
\hline $\begin{array}{l}\text { Example } \\
-20\end{array}$ & 25 & Very severe & \\
\hline $21-30$ & 70 & Extreme $3(=12)$ & $70 \times 12=840$ \\
\hline $31-40$ & 70 & Extreme $3 i=12)$ & $70 \times 12=840$ \\
\hline \multirow{6}{*}{$\begin{array}{l}41-50 \\
51-60 \\
61-70 \\
71-80 \\
81-90 \\
90+\end{array}$} & 50 & Extreme $1(=11)$ & $50 \times 11=550$ \\
\hline & & & \\
\hline & & & \\
\hline & & & \\
\hline & & & \\
\hline & & Total climbing intensity score & 2230 \\
\hline
\end{tabular}




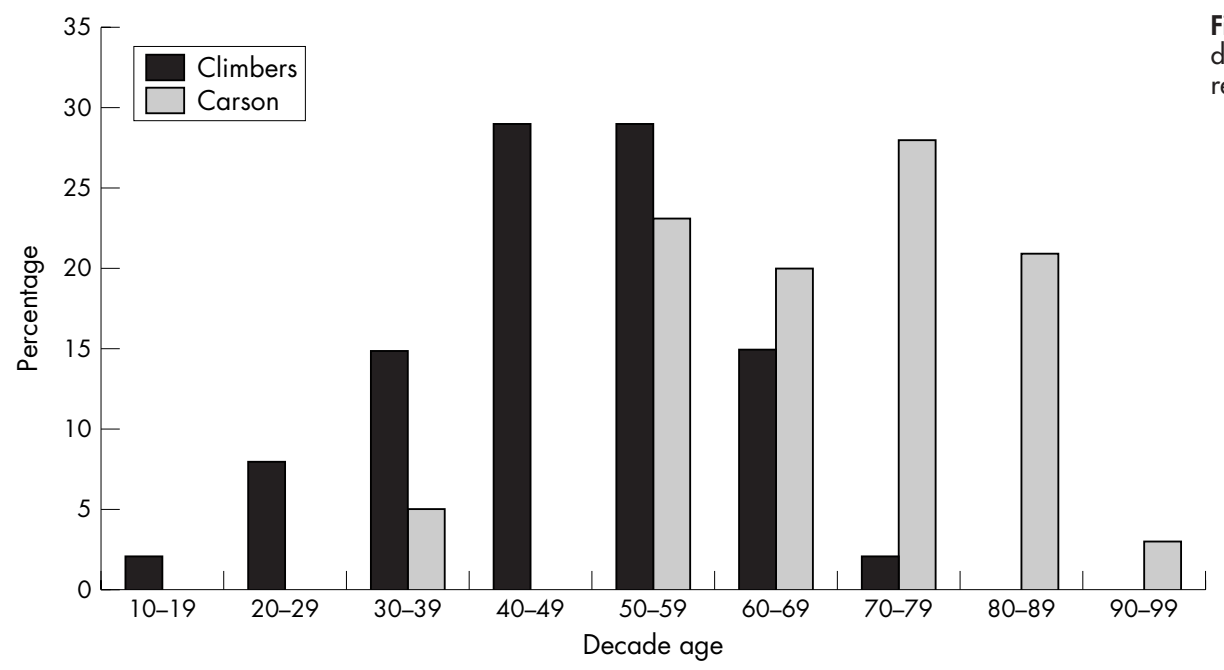

Figure 2 Age of onset of Dupuytren's disease in climbers compared with results from a study by Carson et al. ${ }^{16}$

Grampian region. ${ }^{14}$ In this study the prevalence of Dupuytren's disease in a population of British male climbers was found to be $19.5 \%$. This is much higher than that previously described in some areas of the United Kingdom. A sample of 990 patients attending orthopaedic outpatients departments in the Cotswolds and Chilterns were examined for evidence of Dupuytren's disease, and it was found to be present in 5\% of men (mean age 59). ${ }^{15}$ This prevalence, however, is believed to be low. In a study of 400 male pensioners from Chelsea (mean age 76 years), the prevalence of Dupuytren's was found to be $13.75 \% .{ }^{16}$ Locomotive and office workers in Crewe had an average prevalence of $4 \%$ across all age groups rising to $15.2 \%$ in those aged $65-74$ years. ${ }^{13}$ The prevalence in Teeside was found to be $10.7 \%{ }^{7}$ and $7.4 \%$ in Blackpool. ${ }^{8}$ Lennox et $a l^{14}$ studied the prevalence of Dupuytren's disease in the Grampian region and found it to be $39 \%$ in men, higher than the prevalence found in this study. However, the Grampian region was chosen by Lennox et al because it was believed that the prevalence of Dupuytren's disease was high in this region of north east Scotland. Unfortunately there are few other reports of the prevalence of Dupuytren's disease in the United Kingdom. The true prevalence in men may lie somewhere closer to that of the populations of the Cotswolds, Crewe, Chelsea, Blackpool, and Teeside than that of the Grampian region. On this assumption, the prevalence in climbers is likely to be higher than that of the general population of the United Kingdom. The finger distribution of the disease is similar to that found in other studies, with the ring and little fingers being predominantly involved. ${ }^{15}$

\section{Climbing exposure}

Climbers are able to accurately assess their individual technical climbing grades. The climbing literature when describing various climbing routes details the technical difficulty of each climb. It is important for the climber to

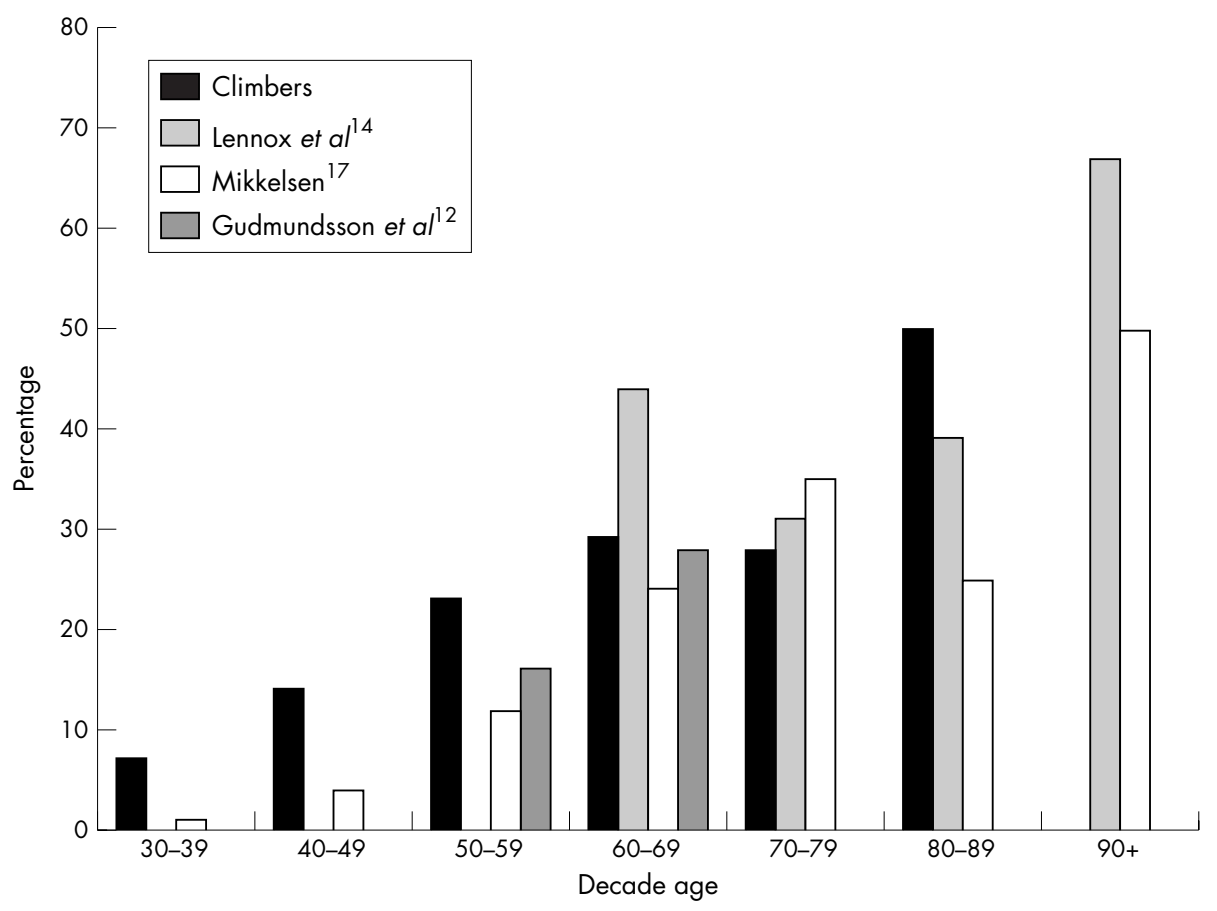

Figure 3 Comparison of the prevalence of Dupuytren's disease in each decade age group in climbers with that found in previous studies. 

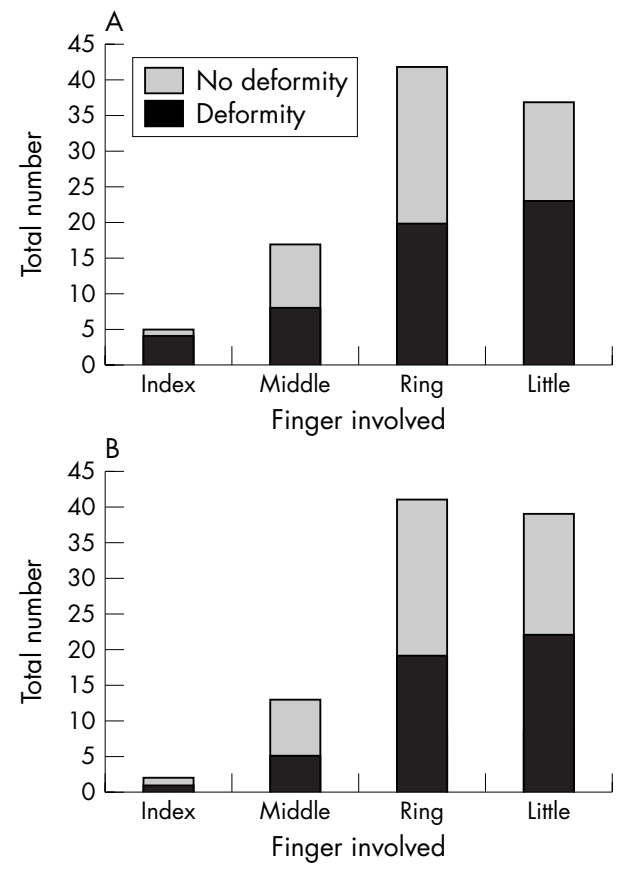

Figure 4 Finger distribution and severity of Dupuytren's disease in climbers. (A) Left hand; (B) right hand.

know their grade before attempting climbs of varying difficulties. There is no standardised technical grading system, and differences exist, for example, between those used in the United Kingdom, United States, France, and Australia. However, these different grading systems can easily be converted between one another. Experienced climbers are comfortable using each system and converting between them. The intensity scores calculated in this study give a good indication of the amount of climbing undertaken by each member to date and the grade at which they climbed. It can then be assumed that the greater the intensity score, the more experienced and therefore more technically able the climber is and the greater the life time exposure to rock climbing.

Climbers with Dupuytren's disease had significantly higher climbing intensity scores than those without, suggesting that the more dedicated and regular climbers are more susceptible to developing the disease. The higher prevalence of Dupuytren's disease with an increasing climbing intensity score may reflect that the climbing experience increases with age and that these climbers are more likely to have developed Dupuytren's disease simply because of age. There is, however, no positive correlation between climber age and climbing intensity score.

\section{Age of onset}

There is an earlier age of onset of disease in climbers compared with the general population (fig 2). In a study by Carson et $a l^{16}$ involving pensioners, most patients with Dupuytren's disease had an age of onset from the 4th decade onwards with most developing it in the 8th decade. This, however, may be inaccurate as the pensioners were asked to recall from memory their age when they first noticed the disease in their hands. In our study, climbers started to develop the disease in the 2nd decade with most cases developing in the 5th and 6th decades. This suggests that being a dedicated climber is a predisposition to earlier development of the disease in those who are susceptible. Looking at the prevalence of Dupuytren's disease in climbers,

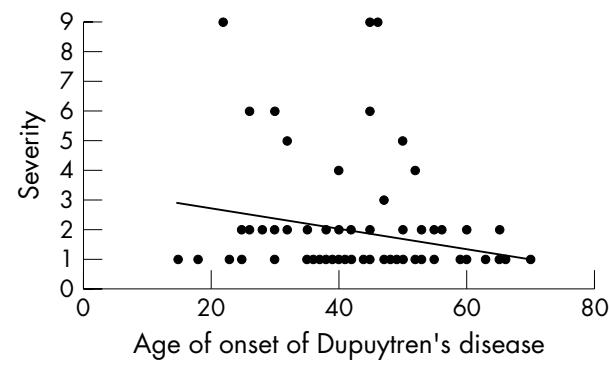

Figure 5 Severity of Dupuytren's disease in relation to age of onset.

there is a much higher proportion of younger climbers with the disease than the general population (fig 3). The sharp increase in prevalence of the disease in the decade ages 45-54 may be explained by the increase in the use of climbing walls in younger climbers for out of season climbing. Early ${ }^{13}$ studied different cohorts in Crewe in the United Kingdom, and Mikkelsen ${ }^{17}$ studied a large Norwegian population sample. Both found a gradual increase in the prevalence of the disease as the age group of the population increased.

\section{Disease severity}

There is a significant positive correlation between the age of onset of Dupuytren's disease and its severity, with an earlier age of onset being associated with greater severity (fig 5). Alternatively, it may be simply an indication of the progressive nature of the disease, with climbers who developed the disease early thus having had the disease for longer at the time of the study.

The proportion of finger contractures in male climbers with Dupuytren's disease is $48 \%$. A study of 1297 men and 868 women from Northwest Europe found the proportion of finger contracture in those with Dupuytren's disease to be $26 \%$ in men. ${ }^{12}$ Early ${ }^{13}$ found, depending on their occupation, that $4-23 \%$ of men in an English population with Dupuytren's disease had finger contractures. A higher proportion of male climbers with Dupuytren's disease have finger contractures than other populations with the disease, suggesting a greater disease severity. There may be a genuine increase in disease severity as a result of rock climbing, or this may simply reflect the earlier age of onset of the disease in the climbers.

\section{Other aetiological factors}

To show that regular rock climbing is a positive aetiological factor for the development of Dupuytren's disease, the conditions or factors that are also associated must be addressed. These include positive family history, diabetes, epilepsy, relation to manual work, smoking, alcohol use, and previous injury, which were all analysed in this study except diabetes. Table 3 summarises the results. A clear association between rock climbing and the development of the disease can be seen having taken into account these other possible associations. The presence of a positive family history was associated with Dupuytren's disease in climbers $(p<0.001)$. Family history may, however, be under-reported, as the climber may be unaware of the disease in older family members such as grandparents. Adjustment for reported family history gives a prevalence of Dupuytren's disease of $15.9 \%$ in men. This again is higher than that found in most other studies. ${ }^{13} 15168$

\section{Sources of bias}

The response rate of $51 \%$ is likely to introduce a bias in favour of over-reporting of Dupuytren's disease as this was the key element of the questionnaire. It can be assumed that those 
Table 3 Other factors in the development of Dupuytren's disease in climbers

\begin{tabular}{llll}
\hline Aetiological factor & Reference & $\begin{array}{l}\text { Climbers with } \\
\text { Dupuytren's } \\
\text { disease }\end{array}$ & $\begin{array}{l}\text { Climbers without } \\
\text { Dupuytren's } \\
\text { disease }\end{array}$ \\
\hline Family history & 1 & $16 \%^{*}$ & $4 \%$ \\
Epilepsy & 2,3 & 0 & $<1 \%$ \\
Smoking & 4,5 & $5 \%$ & $8 \%$ \\
Alcohol & 6 & 15.5 units & 13.95 units \\
Heavy manual workers & 7,8 & $11 \%$ & $10 \%$ \\
Past wrist or hand injury & 9,10 & $56 \%$ & $51 \%$ \\
\hline *Significantly different from climbers without Dupuytren's disease $(\mathrm{p}<0.001)$. &
\end{tabular}

climbers with the disease are more likely to respond to the survey. It is possible that older members of the Climbers Club, especially retired members, are more likely to have taken time to complete and return a large questionnaire. The age distribution of those climbers studied may therefore not accurately reflect the age distribution of the Climbers Club as a whole. However, if it were assumed that all $49 \%$ nonrespondents did not have Dupuytren's disease, then the prevalence would be $9.6 \%$ in male climbers. This is higher than that found by Early ${ }^{13}$ and Mackenney ${ }^{15}$ with a comparative English population of similar average age. Dupuytren's disease reported by the climbers in this study was mainly $(60 \%)$ self diagnosed using detailed pictures and descriptions attached to the questionnaire. The other $40 \%$ were diagnosed by the climber's general practitioner or after referral to an orthopaedic consultant. Self diagnosis is difficult and may be inaccurate, especially in those who self diagnosed thickening of the palmar fascia and nodules. Consultant orthopaedic surgeons can only agree on $76 \%$ of occasions when examining for palmar nodules. ${ }^{14}$ There may therefore be an over-reporting of Dupuytren's disease in those climbers who diagnosed palmar facial thickening or nodules without contractures.

A number of different hand holds are used when ascending a rock face, putting strain on the tendons, pulleys, fascia, and soft tissues of the hand. These are likely to result in repetitive minor trauma to the hand while climbing. The more climbing carried out during a career, the greater the total exposure to such minor hand traumas. Repetitive minor trauma has been suggested to be an aetiological factor in the development of Dupuytren's disease. Thomas and Clarke ${ }^{7}$ assessed 500 claimants considered to have vibration white finger. There was a significantly higher prevalence of Dupuytren's contracture in those with vibration white finger (19.9\%) than in controls $(10.7 \%)$. Bennet ${ }^{8}$ found that the prevalence of Dupuytren's contracture was double in workers involved in bagging and packing compared with other workers in that same plant. Early ${ }^{13}$ did not find any difference in the prevalence of the disease between office workers and manual workers.

We propose that the reason for the increased prevalence, earlier age of onset, and greater severity of Dupuytren's disease in climbers is the repetitive minor trauma that occurs in the palmar fascia while climbing. This study further strengthens the hypothesis that repetitive trauma to the palmar fascia predisposes to the development of Dupuytren's disease in men.

\section{CONCLUSIONS}

- There is a higher prevalence of Dupuytren's disease in committed male rock climbers compared with figures reported for most areas of the United Kingdom.

- Climbers develop the disease at an earlier age compared with the general population.

\section{What is already known on this topic}

The causes of Dupuytren's disease are unclear, although repetitive trauma to the palmar fascia appears to be a predisposing factor.

\section{What this study adds}

- There is a higher prevalence of Dupuytren's disease in committed male rock climbers than in the general population of most areas of the United Kingdom.

- Climbers develop the disease at an earlier age and the disease is more severe.

- This study strengthens the hypothesis that repetitive strain to the palmar fascia over many years is a major factor in the development of Dupuytren's disease in men.

- The disease is more severe in climbers, with a greater proportion of finger contractures.

- The greater the lifetime climbing intensity, the greater the likelihood of a climber having Dupuytren's disease.

- Specific hand injury is unrelated to the development of the disease.

- This study therefore strengthens the hypothesis that repetitive strain to the palmar fascia over many years is a significant factor in the development of Dupuytren's disease in men.

\section{ACKNOWLEDGEMENTS}

We thank the committee and members of the Climbers' Club of Great Britain for distributing, completing, and returning questionnaires.

\section{Authors' affiliations}

A J Logan, N Makwana, Department of Orthopaedics, Wrexhan Maelor Hospital, Cardiff, Wales, UK

G Mason, University of Loughborough, Loughborough, UK

J Dias, University Hospitals of Leicester, Leicester, UK

Competing interests: none declared

\section{REFERENCES}

1 Burge P. Genetics of Dupuytren's disease. Hand Clin 1999;15:63-71.

2 Arafa M, Noble J, Royle SG, et al. Dupuytren's and epilepsy revisited. J Hand Surg $[\mathrm{Br}] 1992 ; 17: 221-4$.

3 Critchley EM, Vakil SD, Hayward HW, et al. Dupuytrens disease in epilepsy: result of prolonged administration of anticonvulsants. J Neurol Neurosurg Psychiatry 1976;39:498-503.

4 Burge $P$, Hoy G, Regan P, et al. Smoking, alcohol and the risk of Dupuytren's contracture. J Bone Joint Surg [Br] 1997;79:206-10. 
5 An HS, Southworth SR, Jackson WT, et al. Cigarette smoking and Dupuytren's contracture of the hand. J Hand Surg [Am] 1988;13:872-4.

6 Bradlow A, Mowat AG. Dupuytren's contracture and alcohol. Ann Rheum Dis 1986:45:304-7.

7 Thomas PR, Clarke D. Vibration white finger and Dupuytren's contracture: are they related? Occupational Medicine (London) 1992;42:155-8.

8 Bennett B. Dupuytren's contracture in manual workers. Br J Ind Med 1982;39:98-100.

9 Kelly SA, Burke FD, Elliot D. Injury to the distal radius as a trigger to the onset of Dupuytren's Disease. J Hand Surg [Br] 1992;17:225-9.

10 McFarlane RM. Dupuytren's disease: relation to work and injury. J Hand Surg [Am] 1991;16:775-9.

11 Murrell AC, Hueston JT. Aetiology of Dupuytren's contracture. Aust N Z J Surg $1990 ; 60: 247-52$
12 Gudmundsson KG, Arngrimsson R, Sigfusson N, et al. Epidemiology of Dupuytren's disease: clinical, serological, and social assessment. The Reykjavik Study. J Clin Epidemiol 2000;53:291-6.

13 Early PF. Population studies in Dupuytren's contracture. J Bone Joint Surg [Br] 1962:44:602-14.

14 Lennox AC, Murali SR, Porter R. A study of the repeatability of the diagnosis of Dupuytren's contracture and its prevalence in the Grampian region. J Hand Surg [Br] 1993;18:258-61.

15 Mackenney RP. A population study of Dupuytren's contracture. Hand 1983;15:155-61.

16 Carson J, Clarke C. Dupuytren's contracture in pensioners at the Royal Hospital Chelsea. J R Coll Physicians Lond 1993;27:25-7.

17 Mikkelsen OA. The prevalence of Dupuytren's disease in norway. Acta Chir Scand 1972;138:695-700.

\section{SPEED RESPONSE TIMES IN SPORT}

O ne of the key features of any professional sport is the speed of the action that occurs within the sport. Given that the average reaction time for an elite athlete varies between 150 and 300 milliseconds (msec), it can be seen from the table below that ball receivers have very limited time to play or adjust their response to the speed of the ball. ${ }^{1}$ In some cases, the receiver must anticipate the nature and direction of the ball based on pre-impact cues.

\begin{tabular}{llll|}
\hline & & & \\
\hline Sport skill & Ball speed & $\begin{array}{l}\text { Distance between } \\
\text { opponents }\end{array}$ & Transit time \\
\hline Heavyweight boxer punch & $38 \mathrm{kph}$ & $0.4 \mathrm{~m}$ & $40 \mathrm{msec}$ \\
Tennis serve & $200 \mathrm{kph}$ & $23.8 \mathrm{~m}$ & $430 \mathrm{msec}$ \\
Baseball pitch & $160 \mathrm{kph}$ & $18.4 \mathrm{~m}$ & $415 \mathrm{msec}$ \\
Cricket fast bowling & $150 \mathrm{kph}$ & $20 \mathrm{~m}$ & $480 \mathrm{msec}$ \\
Soccer penalty kick & $75 \mathrm{kph}$ & $11 \mathrm{~m}$ & $530 \mathrm{msec}$ \\
\hline
\end{tabular}

\section{REFERENCE}

1 Farrow D, Kemp J. Run like you stole something the science behind the score line. Crows Nest, Australia: Allen \& Unwin, 2003:3. 